\title{
RIDE AND HANDLING ANALYSIS FOR AN ACTIVE ANTI-ROLL BAR: CASE STUDY ON COMPOSITE NONLINEAR CONTROL STRATEGY
}

\author{
N. Zulkarnain ${ }^{1}$, H. Zamzuri ${ }^{1 *}$ and S.A. Mazlan ${ }^{2}$ \\ ${ }^{1}$ Vehicle System Engineering Research Laboratory \\ Universiti Teknologi Malaysia, Jalan Semarak, Malaysia \\ *Email: hairi.kl@utm.my \\ ${ }^{2}$ Malaysia-Japan International Institute of Technology \\ Universiti Teknologi Malaysia, Jalan Semarak \\ Malaysia
}

\begin{abstract}
This paper presents a comparison of ride and handling analysis for an active anti-roll bar system using various types of controller. Work using conventional and modern control approaches has been investigated by previous researches. This study further extends this work by investigating a particular modern control technique using a linear quadratic regulator, linear quadratic Gaussian and composite nonlinear feedback controller in designing the closed loop feedback for an anti-roll bar system control scheme. A simple linear quadratic regulator and a linear quadratic Gaussian are first investigated. An active anti-roll bar system has to balance the trade-off between ride comfort and handling performance. The new linear quadratic Gaussian composite nonlinear feedback (LQG-CNF) fusion control strategy is developed to improve the performances on vehicle ride comfort and handling for an active anti-roll bar system. The linear half car model is combined with a single track model with roll dynamics. The performance of the controllers is compared and the simulation results show that the proposed control strategy gives better performance in terms of vehicle ride comfort and handling.
\end{abstract}

Keywords: Active anti-roll bar; ride comfort; handling; composite nonlinear feedback.

\section{INTRODUCTION}

A suspension element used at the front, rear, or at both ends of a car that reduces body roll by resisting any unequal vertical motion between the pair of wheels to which it is connected is called an anti-roll bar (ARB). Figure 1 illustrates an anti-roll bar that is connected with the left and right wheel. The main functions of the automotive anti-roll bar system are to provide vehicle support, stability and directional control during handling manoeuvres and to provide effective isolation from road disturbances [1]. A ground vehicle design typically represents a trade-off between ride comfort and handling criteria [2]. Ride is used to define and measure how well the vehicle isolates its occupants from road surface irregularities such as bumps and potholes. If a vehicle has good ride characteristics, this means it will be comfortable to travel in. Meanwhile, handling is defined by the quality of handling, which relates to subjective feelings of the human driver and also objective measurement of the vehicle characteristics [3, 4]. 


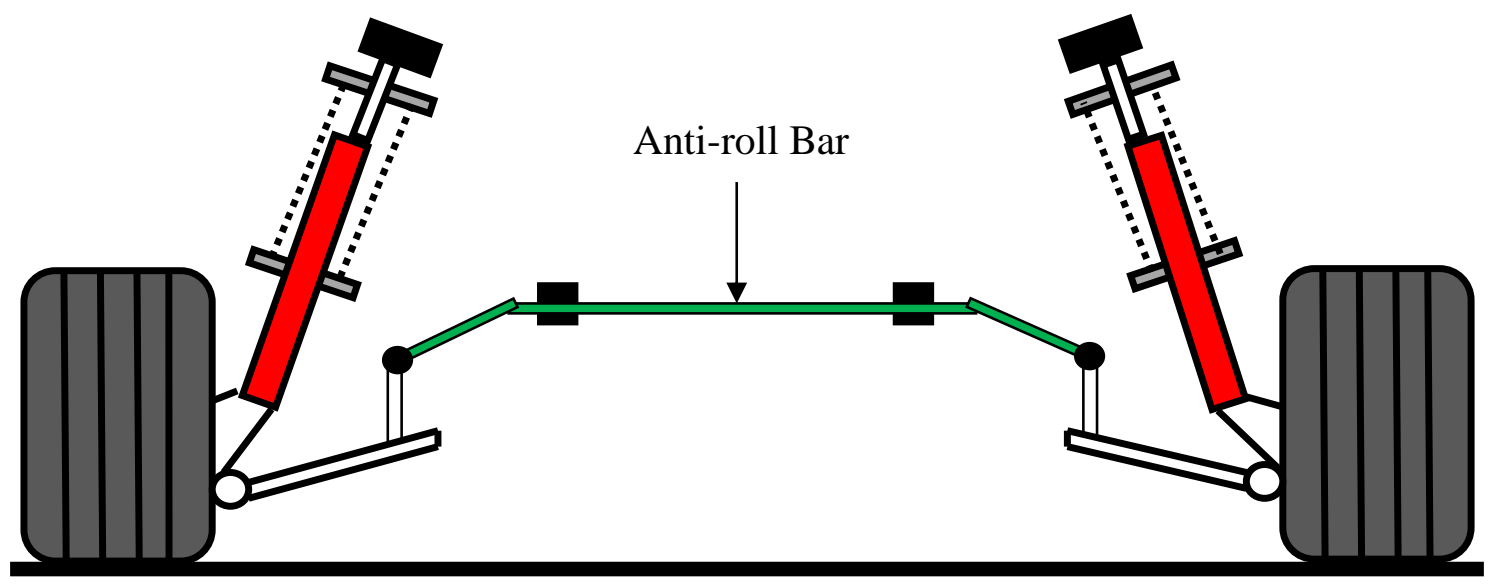

Figure 1. Schematic presentation of an anti-roll bar in action [1].

Unfortunately, there are trade-offs between ride and handling and it is a challenge for the automotive engineer to make a vehicle with a good ride and good handling at the same time. Many studies have been done on active system to tackle this trade-off. Some prefer to develop active suspension, while others prefer to focus on advancing the anti-roll bar. However, from the manufacturer's point of view, cost is the key factor. In this factor, the anti-roll bar system has the advantage since it can provide a solution to the ride and handling trade-off at a lower cost than active suspension. The advantages of a passive anti-roll bar are to reduce the body roll acceleration and roll angle during the single wheel lifting and cornering manoeuvre. By reducing the body roll motion, the driving safety and handling stability will be greatly improved $[5,6]$. However, the passive anti-roll bar also has disadvantages. During a cornering manoeuvre, the anti-roll bar will transfer the vertical forces of one side of the suspension to the other side and therefore create moments against lateral force. Unfortunately, during straight line driving, lateral forces induced by road irregularities will also have the same effect as is induced by the cornering manoeuvre and therefore reduce ride comfort. For that reason, an active anti-roll bar is developed to improve the disadvantages of the passive anti-roll bar while at the same time augmenting ride comfort and handling performance. But the anti-roll bar has recently become very popular among researchers to tackle the issues of the trade-off between ride and handling [7-9]. Cronjé and Els studied the effect of the active anti-roll bar on ride comfort and handling of an off-road vehicle [10,11]. They also analysed the use of anactive anti-roll bar as a means of improving the handling of an off-road vehicle without sacrificing ride comfort [11]. In order to improve the vehicle performance in this area, a lot of control schemes have been proposed in the framework of a computercontrolled suspension system such as an active or semi-active suspension system $[4,6]$. Danesin, Krief [12] have successfully designed an active roll control system to increase handling and ride comfort [12]. Some studies investigating the use of preview control have predicted potential benefits.

Yamamoto and Nishimura proposed a design strategy for the control system for electric power steering (EPS) in consideration of the active ARB in order to avoid sideeffects on the steering system from the reaction force of the front tyre due to roll stiffness control for the active ARB[13]. Gain-scheduled (GS) control is used in designing the EPS method to properly assist the driver in steering according to the vehicle speed and to realize hydraulic power steering (HPS) with a steering feeling. The 
active $\mathrm{ARB}$ is obtained using linear quadratic control theory in order to balance competing goals for roll reduction on cornering and suppression of rolling vibration on rough roads [13]. An active ARB has an actuator which can actively generate the torque at the centre of an ARB. It is verified that the control system designed can settle the rolling vibration on a rough road more quickly than a vehicle model with normal suspension while reducing the steady roll angle during cornering. Besides, an electric ARB system has been developed as a technology for controlling vehicle roll angle performance by $[14,15]$. Moreover, Gosselin-Brisson et al. designed an active anti-roll bar using a full state feedback optimal control strategy by using a linear quadratic regulator (LQR) method. All the state variables have to be measured by electronic sensors for this control method. A controller using four different measurements proves to be more efficient than any passive system for the vehicle studied. A graphical method has been presented for selection of the ARB stiffness based on selecting appropriate parameters [16]. Besides that, R.C. Lin et al. used lateral acceleration control and an optimal controller based on an LQR theory to design active roll control systems for heavy goods vehicles. The controller designed for the active system uses the full state feedback control strategy [17]. The suspension consists of a limited bandwidth hydraulic actuator in series with an anti-roll bar. The procedure used to determine suitable controller gains is described. The proposed design of a controller by the author for an active anti-roll system is a compromise between several parameters, such as the roll angle, lateral load transfer, power consumption and actuator bandwidth. Furthermore, the suspension must be suitable for a wide range of operating conditions. In order to balance the conflicting requirements, an optimization strategy is needed.

The composite nonlinear feedback (CNF) control is one nonlinear control technique that has been developed in the last decade based on state feedback law. This technique was introduced in [18] for tracking control of a $2^{\text {nd }}$ order linear system and has been improved for a higher order MIMO linear system in [19]. It was further explored and extended for use in a general multivariable system with input saturation in [20], a linear system with actuator nonlinearities in [21], as well as a hard disk drive servo system and servo positioning system with disturbance in [22-25]. Recently, CNF has been applied in vehicle dynamics control, particularly for an active suspension system in order to improve suspension deflection, velocity of the car body, tyre deflection, velocity of the car wheel and body acceleration [26] and especially for improving the transient response of the tracking control that has been examined for vehicle yaw rate tracking control. In principle, the use of CNF control can improve the performance of the transient response based on a variable damping ratio concept. The CNF control keeps a low damping ratio during transient, which is varied to a high damping ratio as the output response comes close to the reference set point. A CNF control that consists of linear and nonlinear feedback control law is designed in three important steps which will be discussed later to realize this concept. Therefore, based on previous studies and the above discussion, the advantages of the CNF control technique are clear.

The control algorithm called the conventional composite nonlinear feedback (CCNF) control was introduced by [27] to achieve the best transient response that can reduce the overshoot on the sprung mass and angle of the control arm of a MacPherson active suspension system. This paper describes the mathematical modelling and control of a nonlinear active suspension system for ride comfort and road handling performance by using the multi-body dynamics software CarSim. For ride quality and road handling tests, the integration between Matlab/SIMULINK and multi-body dynamics system 
software is proposed. The numerical experimental results show the control performance of CCNF compared with the linear quadratic regulator (LQR) and passive system. However, the CNF control law has so far not yet been implemented in the active ARB suspension system. This motivated us to apply the CNF control technique to improve the performance of the active ARB system as the contribution of this study. In this paper, the CNF control technique is successfully applied to design the ARB controller. The designed control strategy is verified in simulation. The simulation results demonstrate the improvement of the active ARB system performance using the LQGCNF fusion compared to the LQR, LQG and CNF control strategy. The outline of this paper is divided into four sections. In the next section, the dynamic mathematical modelling of an active ARB system is introduced. The control technique and design are applied to design the control laws for the active ARB system in Section 3. The simulation and comparison results will be presented in Section 4 and finally, the concluding remarks are drawn.

\section{MATHEMATICAL MODELLING}

The model represents the front view of a vehicle suspension system as shown in Figure 2. It includes four degrees of freedom (DOF) to model an independent suspension instead of the three DOF commonly used in the literature, where the right and left unsprung masses are modelled by one axle only. For this work, the vehicle assumed has the same parameters on the right and left sides, which is generally true. Tyre damping is ignored in this model. The sprung mass gravity centre (CG) is in the middle of the track. The vehicle suspension model is based on a half car model from the front view and a single track model with roll dynamics developed from the bicycle model.

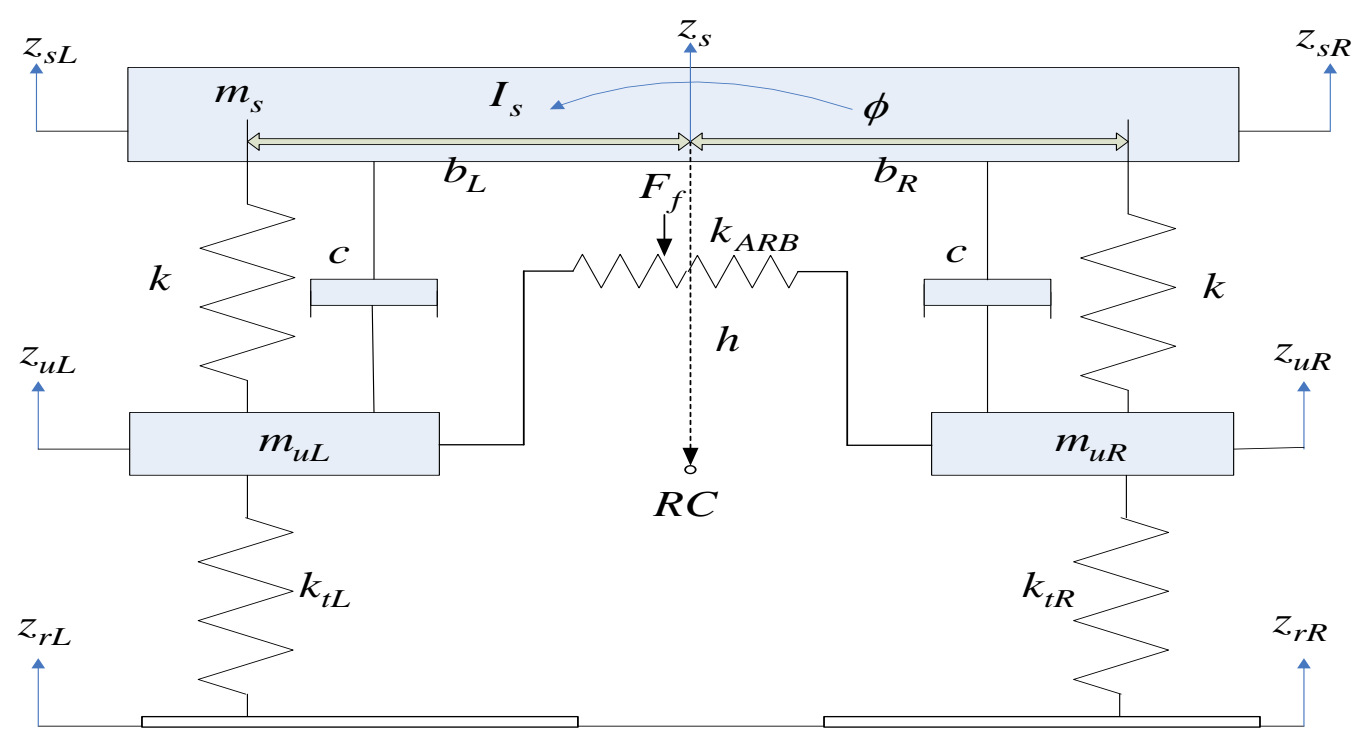

Figure 2. Half car model of a vehicle from front view. 


\section{Half-Car Model}

The half car model explains the relation between body bounce, body roll angle, left and right wheels hop and road excitations. Then, the equations of motions for this model are combined with the single track model with roll dynamics to design the four degrees of freedom vehicle dynamic model as follows:

Body vertical acceleration:

$$
\ddot{z}_{s}=-\frac{2 c \dot{z}_{s}}{m_{s}}+\frac{c \dot{z}_{u L}}{m_{s}}+\frac{c \dot{z}_{u R}}{m_{s}}+\frac{c\left(b_{L}-b_{R}\right)}{m_{s}} \dot{\phi}-\frac{2 k z_{s}}{m_{s}}+\frac{k z_{u L}}{m_{s}}+\frac{k z_{u R}}{m_{s}}-\frac{k\left(b_{L}-b_{R}\right)}{m_{s}} \phi
$$

where $\ddot{z}_{s}$ is body vertical acceleration, $\dot{z}_{s}$ is body deflection, $z_{s}$ is body displacement, $\dot{z}_{u L}$ is left wheel deflection, $z_{u L}$ is left wheel displacement, $\dot{z}_{u R}$ is right wheel deflection, $\dot{\phi}$ is roll rate, $\phi$ is roll angle, $b_{L}$ is length for centre of gravity to the left wheel suspension, $b_{R}$ is length for centre of gravity to the right wheel suspension, $c$ is damping stiffness, $k$ is spring stiffness and $m_{s}$ is sprung mass weight.

Left wheel vertical acceleration:

$$
\ddot{z}_{u L}=\frac{k z_{s}}{m_{u L}}-\frac{\left(k+k_{t L}\right)}{m_{u L}} z_{u L}+\frac{c \dot{z}_{s}}{m_{u L}}-\frac{c \dot{z}_{u L}}{m_{u L}}+\frac{k b_{L}}{m_{u L}} \phi+\frac{c b_{L}}{m_{u L}} \dot{\phi}+\frac{k_{t L}}{m_{u L}} z_{r L}+F_{L}
$$

where $\ddot{z}_{u L}$ is left wheel vertical acceleration, $z_{u L}$ is left wheel displacement, $z_{r L}$ is left road excitation, $m_{u L}$ is left unsprung mass weight, $k_{t L}$ is left tyre stiffness, and $F_{L}$ is left force of anti-roll bar.

Right wheel vertical acceleration:

$$
\ddot{z}_{u R}=\frac{k z_{s}}{m_{u R}}-\frac{\left(k+k_{t R}\right)}{m_{u R}} z_{u R}+\frac{c \dot{z}_{s}}{m_{u R}}-\frac{c \dot{z}_{u R}}{m_{u R}}-\frac{k b_{R}}{m_{u R}} \phi-\frac{c b_{R}}{m_{u R}} \dot{\phi}+\frac{k_{t R}}{m_{u R}} z_{r R}-F_{R}
$$

where $\ddot{z}_{u R}$ is right wheel vertical acceleration, $z_{u R}$ is right wheel displacement, $z_{r R}$ is right road excitation, $m_{u R}$ is right unsprung mass weight, $k_{t R}$ is right tyre stiffness, and $F_{R}$ is right force of anti-roll bar.

Roll acceleration of half car model: 


$$
\begin{gathered}
\ddot{\phi}=-\frac{\left(b_{L}-b_{R}\right) k z_{s}}{I_{s}}+\frac{\left(b_{L} k z_{u L}\right)}{I_{s}}-\frac{\left(b_{R} k z_{u R}\right)}{I_{s}}-\frac{c\left(b_{L}-b_{R}\right) \dot{z}_{s}}{I_{s}}+\frac{b_{L} c \dot{z}_{u L}}{I_{s}}-\frac{b_{R} c \dot{z}_{u R}}{I_{s}}-\frac{\left(k b_{L}^{2}+k b_{R}^{2}\right)}{I_{s}} \phi \\
-\frac{c\left(b_{L}^{2}+b_{R}^{2}\right)}{I_{s}} \dot{\phi}+e F_{f}
\end{gathered}
$$

where $\ddot{\phi}$ is roll acceleration of half car model, $I_{s}$ is roll axis moment inertia, $e$ is mounting location of anti-roll bar, and $F_{f}$ is force magnitude calculated by the controller.

\section{The Linear Single Track Model with Roll Dynamics}

The simplest vehicle model is the linear single track model, also known as the bicycle model, which is obtained by approximating the front and rear pairs of wheels as single wheels. The model is illustrated in Figure 3. Assuming that the steering angle is small, the equations of motion are given by Pacejka [28].

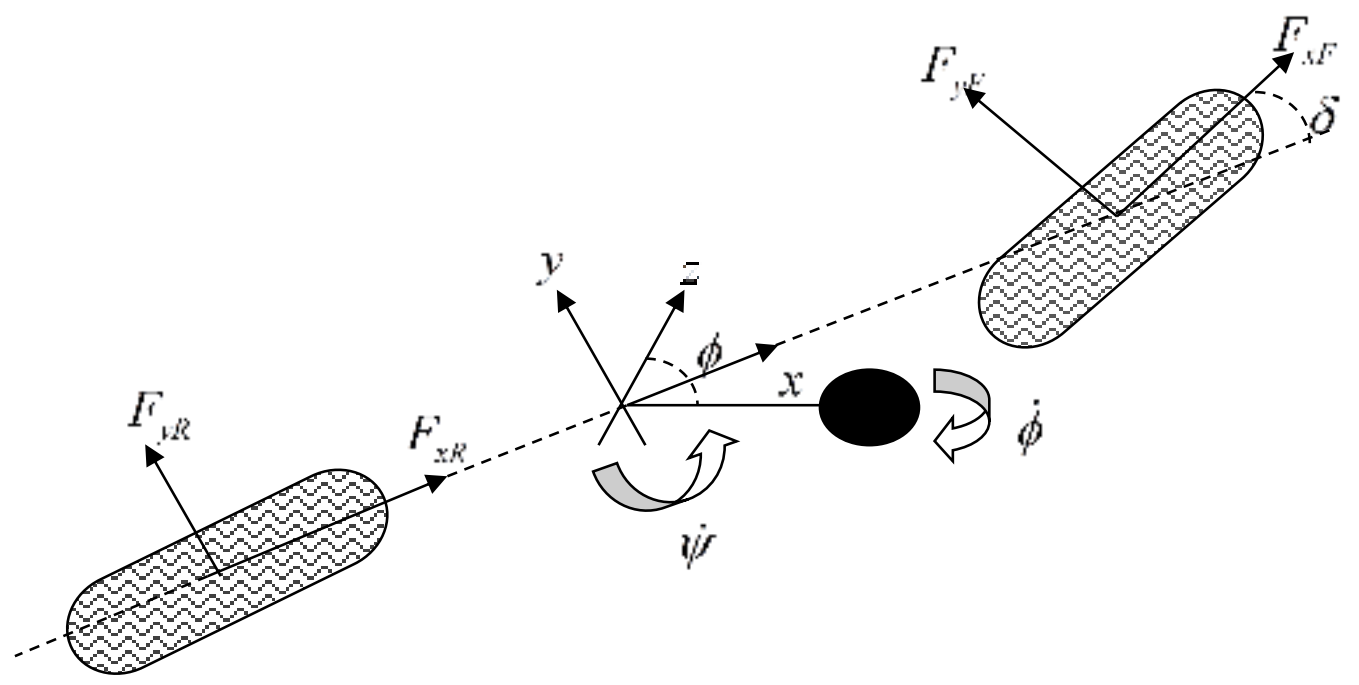

Figure 3. Singletrack model, showing the combined front and rear tyre forces, the steering angle, the yaw rate, and the vehicle sideslip angle [28].

Lateral motion:

$$
m\left(\dot{V}_{y}+\dot{V}_{x} \dot{\psi}\right)=F_{y F}+F_{y R}
$$

where $m$ is sprung mass weight, $\dot{V}_{y}$ is lateral acceleration, $\dot{V}_{x}$ is longitudinal velocity, $F_{y F}$ is front lateral tyre force, $F_{y R}$ is rear lateral tyre force, and $\dot{\psi}$ is yaw rate. 
Yaw rate:

$$
\begin{gathered}
I_{z z} \ddot{\psi}=a F_{y F}-b F_{y R} \\
I_{x x} \ddot{\phi}+C_{q} \dot{\phi}+K_{q} \phi=m h\left(\dot{V}_{y}+V_{x} \dot{\psi}\right) \\
F_{y F} \approx C_{f} \alpha_{F} \\
F_{y R} \approx C_{r} \alpha_{R}
\end{gathered}
$$

where $I_{z z}$ is moment of inertia around the $z$-axis, $\ddot{\psi}$ is yaw acceleration, and $a$ is distance from the front wheel to the centre of gravity, $b$ is distance from the rear wheel to the centre of gravity, $I_{x x}$ is moment of inertia around the $x$-axis, $\phi$ is roll angle, $\dot{\phi}$ is roll rate, $\ddot{\phi}$ is roll acceleration, $C_{q}$ is damping coefficient, $K_{q}$ is spring coefficient, $h$ is distance from roll axis to centre of gravity, $V_{x}$ is longitudinal velocity, $C_{f}$ is front cornering stiffness, and $C_{r}$ is rear cornering stiffness. The slip angles of the front, $\alpha_{F}$, and rear wheels, $\alpha_{R}$, can be approximated as Eq. (10) and Eq. (11.):

$$
\begin{gathered}
\alpha_{F} \approx \delta-\frac{1}{V_{x}}\left(V_{y}+\alpha \dot{\psi}\right) \\
\alpha_{R} \approx-\frac{1}{V_{x}}\left(V_{y}-b \dot{\psi}\right)
\end{gathered}
$$

The input to the system is the steering angle while the outputs of the system are lateral velocity, yaw rate and roll rate. The transfer function equations single track model with roll dynamics system is written as follows:

Lateral acceleration:

$$
\dot{V}_{y}=\frac{C_{f}}{m}\left[\delta-\frac{1}{V_{x}}\left(V_{y}+a \dot{\psi}\right)\right]+\frac{C_{r}}{m}\left[-\frac{1}{V_{x}}\left(V_{y}-b \dot{\psi}\right)\right]-\dot{V}_{x} \dot{\psi}
$$

Yaw acceleration:

$$
\ddot{\psi}=\frac{a C_{f}}{I_{z z}}\left[\delta-\frac{1}{V_{x}}\left(V_{y}+a \dot{\psi}\right)\right]-\frac{b C_{r}}{I_{z z}}\left[-\frac{1}{V_{x}}\left(V_{y}-b \dot{\psi}\right)\right]
$$

Roll acceleration of single track model:

$$
\ddot{\phi}=\frac{m h}{I_{x x}}\left(\dot{V} y+V_{x} \dot{\psi}\right)-\frac{C_{q} \dot{\phi}}{I_{x x}}-\frac{K_{q} \phi}{I_{x x}}
$$




\section{Anti-roll Bar System}

Three different cases are analysed which are passive suspension without ARB, passive suspension with passive ARB and passive suspension with active ARB. Each case is modelled by different roll control force equations. The suspension is composed of a spring and a damper for each side of the vehicle. in the case of passive suspension without $\mathrm{ARB}$, the roll control forces are eliminated, because the only roll stiffness is provided by the suspension spring and damper [16].

$$
\begin{aligned}
F_{R} & =0 \\
F_{L} & =0
\end{aligned}
$$

The passive suspension with passive ARB model is representative of most common vehicles in use today. To reduce roll motion, an ARB is added to the suspension system, increasing the total roll stiffness. The ARB is usually made of steel and acts like a spring connected to the right and left unsprung masses. The ARB force is a function of the difference between right and left suspension deflection. The force is applied by the bar on each side of the vehicle so that the left force has the same magnitude and the opposite direction to the right one. For an ARB stiffness $k_{A R B}$, the force corresponds to:

$$
F_{A R B}=-k_{A R B} \frac{\left[\left(z_{s R}-z_{u R}\right)-\left(z_{s L}-z_{u L}\right)+w \phi\right]}{L}
$$

where $w$ is length of anti-roll bar arm and $L$ is length of anti-roll bar.

To model the passive ARB, the forces $F_{R}$ and $F_{L}$ are given by Eq. (18) and (19).

$$
\begin{gathered}
F_{R}=F_{A R B}=-k_{A R B} \frac{\left[\left(z_{s R}-z_{u R}\right)-\left(z_{s L}-z_{u L}\right)+w \phi\right]}{L} \\
F_{L}=-F_{A R B}=k_{A R B} \frac{\left[\left(z_{s R}-z_{u R}\right)-\left(z_{s L}-z_{u L}\right)+w \phi\right]}{L}
\end{gathered}
$$

For a passive suspension with an active anti-roll bar model, the force is applied with the same magnitude but in opposite directions to for the passive anti-roll bar. In this study, the force magnitude $F_{f}$ is calculated by the controller. As a result, the forces are applied as in Eq. (20) and (21).

$$
\begin{gathered}
F_{R}=F_{f}=\frac{T_{A R B}}{L} \\
F_{L}=-F_{f}=-\frac{T_{A R B}}{L}
\end{gathered}
$$

Three different inputs can be applied to the models: lateral force, left and right road motion. The application of left and right road motion with equal phase and 
amplitude results in pure vertical motion similar to the quarter model behaviour. Since this model is extensively studied in the literature, it isn't detailed in this paper. On the other hand, the excitation of a single wheel gives a valuable indication on how the system transfers the road perturbation from one side to the other. Since the ARB has a noticeable impact on this transfer, the first case studied is the application of a road motion input to a single wheel. Since the side of the excitation application doesn't change the response amplitude, the input is applied at the right tyre/road interface. In real-life use of a ground vehicle, cornering manoeuvres are unavoidable. The change in trajectory is accomplished by creating a lateral acceleration. Since the response of the vehicle's suspension during these manoeuvres are critical for stability, lateral acceleration input is the second case studied in this work.

The roll motion is caused by the vehicle's lateral acceleration, $a_{y}$ which depends on the speed and corner radius. In a manner similar to the road perturbation, the direction of the force only changes the direction of the response, since the vehicle is symmetrical. For this work, a right turn is simulated, resulting in a left acceleration creating a force at the sprung mass. Since the force is applied at a distance $h$ from the rotation centre, a moment $M_{s}$ is created on the sprung mass with a magnitude given by Eq.(22).

$$
M_{s}=a_{y} m_{s} h
$$

\section{CONTROLLER DESIGN}

\section{Linear Quadratic Gaussian}

The theory of LQG control design is well known, and it is summarised below. Consider the state-space model of the process in the form of

$$
\begin{gathered}
\dot{x}=A x+B u+\Gamma w \\
y=C x+v
\end{gathered}
$$

where $x \in \square^{n \times 1}$ and $u \in \square^{m \times n}$ and $y \in \square^{q \times 1}$, while $w$ and $v$ are white uncorrelated process and measurement noises, respectively. In the state-feedback version of the LQR, it is assumed that the whole state $\mathrm{x}$ can be measured and is therefore available for control. The state-feedback controller is given by

$$
\begin{aligned}
& u=-K_{r} x \\
& K_{r}=R^{-1} B^{T} P
\end{aligned}
$$

where $K_{r}$ is the gain matrix and subject to minimizing the quadratic cost function given by

$$
J=\int_{0}^{\infty}\left[x^{T}(t) Q_{r} x(t)+u^{T}(t) R_{r} u(t)\right] d t
$$

where state weighting matrix $Q$ is a $n \times n$ symmetric positive definite matrix and control weighting matrix $R$ is a $m \times m$ symmetric positive definite matrix. 
The gain matrix $K$ is the solution matrix Riccati differential equation which is subject to given values of $A, B, C, Q$ and $R$ given by

$$
A^{T} P+P A+\dot{P}+Q=P B R_{k}^{-1} B^{T} P
$$

If $P$ is constant, then $\dot{P}=0$, and the Riccati equation can be simplified to

$$
A^{T} P+P A+\dot{P}+Q-P B R_{k}^{-1} B^{T} P=0
$$

and the solution of the gain matrix is given by

$$
K_{r}=R_{k}^{-1} B^{T} P
$$

subject to $(A, B)$ being stabilisable $R_{k}$ and $Q \geq 0$ is positive definite and positive semidefinite. $(Q, A)$ has no unobservable modes on the imaginary axis.

The LQR part guarantees the closed loop stability with an appropriate choice of weighting matrices $Q$ and $R$ variables. Since not all states parameters can be measured directly, an estimator is used for the entire state vector with respect to the plant's output. The estimator is given by

$$
\begin{aligned}
\dot{\hat{x}} & =A \hat{x}+K_{f}(y-C \hat{x}) \\
& =\left(A-K_{f} C\right) \hat{x}+K_{f} y
\end{aligned}
$$

where $K_{f}$ is the estimator filter gain matrix given as

$$
K_{f}=P_{f} C^{T} R_{f}^{-1}
$$

The covariance vector $P_{f}$ of the estimated state variable is obtained by solving the algebraic Riccati equation:

$$
A P_{f}+P A^{T}-P_{f} C^{T} R_{f}^{-1} C P_{f}+B Q_{f} B^{T}=0
$$

where $Q_{f}=E\left(\omega \omega^{T}\right), R_{f}=E\left(v v^{T}\right)$ are process and sensor noise covariances.

\section{Composite Nonlinear Feedback Controller}

Composite nonlinear feedback (CNF) control is a nonlinear control technique, which contains the composition of a linear feedback law and a nonlinear feedback law without any switching element. In other words, linear and nonlinear laws in this type of algorithm are working simultaneously all the time. In this method, the linear feedback objective is to get a small damping ratio for quick response without at the same time exceeding the nature of the actuator limits. Meanwhile, the non-linear feedback is designed to increase the damping ratio as the system output approaches the target reference to avoid an overshoot occurring [26]. A linear continuous time system with actuator saturation can be expressed in general state space as follows: 


$$
\begin{gathered}
\dot{x}(t)=A x(t)+B \operatorname{sat}(u(t)), x(0)=x_{0} \\
y(t)=C_{1} x(t) \\
h(t)=C_{2} x(t)
\end{gathered}
$$

where $x \in \square^{n}, u \in \square^{m}, \mathrm{y} \in \square^{p}$, and $h \in \square^{l}$ are the state vector, control input, measurement output and controlled output vector respectively. $A, B, C_{1}$ and $C_{2}$ are appropriate dimensional constant matrices, and sat: $\mathbb{R} \rightarrow \mathbb{R}$ represents actuator saturation, which can be defined as

$$
\operatorname{sat}(u)=\operatorname{sgn}(u) \min \left\{u_{\max },|u|\right\}
$$

In Eq. (38), $u_{\max }$ is a saturation level of actuator input. To apply CNF, the following assumptions of system matrices are considered.

1. $(A, B)$ is controllable (stabilisable),

2. $\left(A, C_{1}\right)$ is observable (detectable), and

3. $\left(A, B, C_{2}\right)$ is invertible and there is no invariant zero at $\mathrm{s}=0$.

In this research, the controller is designed based on the state feedback case $(y=x)$ where the assumption is made that all states of plant are available to measure, even though in most cases an observer is needed to estimate immeasurable states. There are three steps involved in the CNF design, which are linear feedback design to get the optimal response, nonlinear feedback design to prevent overshoot, then finally a merging of both feedbacks to work together. Details of these steps are as follows:

Step 1: Design a linear feedback law.

$$
u_{L}=F x+G r
$$

where $r$ is zero and $F$ is chosen such that $A+B F$ are an asymptotically stable and closed loop system $C_{2}(s I-A-B F)^{-1}$ having certain desired properties such as a low damping ratio. Selection of matrix $F$ is not unique and can be found using an optimization method such as $H_{2}$ and $H_{\infty}$ approaches. Besides, matrix $G$ is scalar and given by

$$
\left.G=-\left[C_{2}(A+B F)^{-1} B\right)\right]^{-1}
$$

Step 2: Design a nonlinear feedback law.

$$
u_{N}=\rho(y, r) B^{T} P\left(x-x_{e}\right)
$$


where $\rho(y, r)$ is any non-positive local Lipschitz in $\mathrm{x}$ such as $-\beta e^{-\alpha \alpha_{0}|y-r|}$. This function is used to change the damping ratio of the closed loop system when the output approaches the reference given. This nonlinear function is not unique and there are solutions to obtain the optimal value of the tuning parameter that will be explained later. Matrix $P$ exists since $A+B F$ is asymptotically stable and can be obtained from the following Lyapunov equation:

$$
(A+B F)^{T} P+(A+B F) P=-W
$$

There are proper ways to find a suitable value of $W$ which is positive definite as proposed by [18]. However, in this research $W$ is simplified as the matrix identity. In another term, equilibrium point $x_{e}$ is obtained by

$$
x_{e}=G_{e} r
$$

where

$$
G_{e}=-(A+B F)^{-1} B G
$$

Step 3: Combination of linear and nonlinear feedback laws.

$$
u=u_{L}+u_{N}=F x+G r+\rho(y, r) B^{T} P\left(x-x_{e}\right)
$$

In this research, tuning parameters $\alpha$ and $\beta$ as proposed by [26] have been used. The first parameter $\beta$ can be found by setting the desired damping ratio of the closed loop system, $\xi_{\infty}$ :

$$
\dot{\tilde{x}}=\left(A+B F-\beta B B^{T} P\right) \tilde{x}
$$

whereas the optimal value $\alpha$ is obtained by solving the minimization of some appreciable criteria, such as the integral of absolute error (IAE) and integral of timemultiplied absolute value of error (ITAE) as given in the equations:

$$
\min _{\alpha} \int_{0}^{\infty}|e| d t \text { or } \min _{\alpha} \int_{0}^{\infty} t|e| d t(47)
$$

where

$$
e=y-r
$$

\section{RESULTS AND DISCUSSION}

This section will present the design process of the proposed controller. The objective of the active ARB controller is to reject disturbance and to improve the roll angle and roll rate response as close to zero. The controllers used in this work are linear quadratic Gaussian (LQG) and composite nonlinear feedback (CNF) controllers. These are 
designed and tuned to generate the input of torque to control the active ARB system. Figure 4 shows the block diagram configuration that has been used for the combination of the CNF controller, LQR controller and Kalman filter estimator to form a compensator. This solution is based on the separation principle, where the LQR and Kalman filter are designed independently and then combined to form the LQG compensator. The CNF controller has two parts, which are a linear feedback part and a nonlinear feedback part. The objective of linear feedback is to get a small damping ratio for quick response and nonlinear feedback is designed to increase the damping ratio as the system output approaches the target reference to avoid overshoot [29-32]. In this work, the target reference is zero.

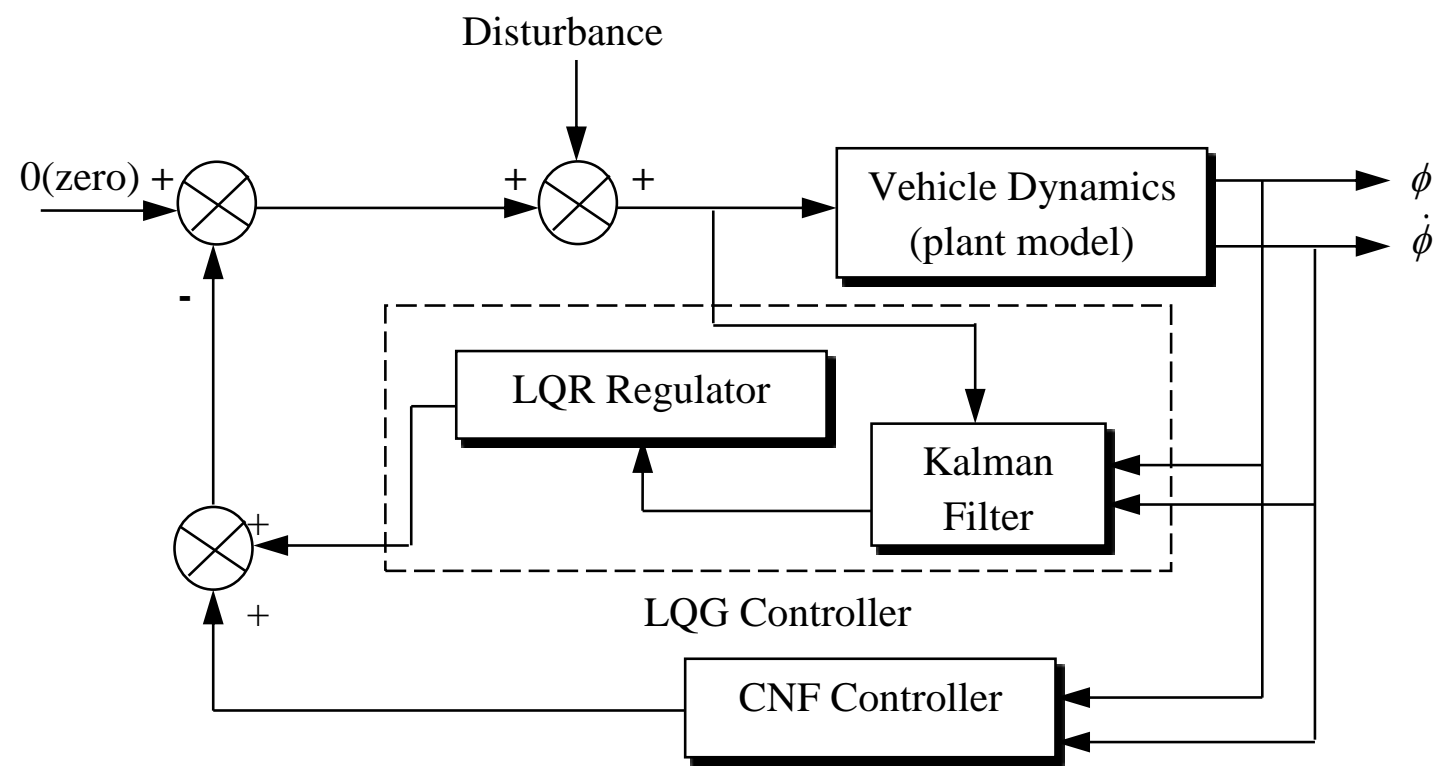

Figure 4. LQG + CNF block diagram configuration.

The linear control law for torque of the anti-roll bar is defined as

$$
\mid T_{A R B}=\text { Disturbance }-\left(K_{l q r} \dot{\hat{x}}+F x+G r+\rho(y, r) B^{T} P\left(x-x_{e}\right)\left[\begin{array}{l}
\phi \\
\dot{\phi}
\end{array}\right]\right) \mid
$$

where:

$$
K_{l q r}=R B^{T} P_{l q r}, \quad \dot{\hat{x}}=A \hat{x}+K_{f}(y-C \hat{x}), r=0, \rho(y, r)=-\beta e^{-\alpha \alpha_{0}|y-r|}, x_{e}=G_{r} r
$$

The value of $P$ is obtained from the Lyapunov method in Eq. (42).

Then, the states are:

$$
x=\left[\begin{array}{llllllllll}
z_{s} & z_{u R} & z_{u L} & \dot{z}_{s} & \dot{z}_{u R} & \dot{z}_{u L} & \phi & \dot{\phi} & V_{y} & \dot{\psi}
\end{array}\right]^{T}
$$


Parameters tuning for LQG and CNF control strategy is discussed. First, the parameters of the LQR controller gain are tuned by using Bryson's Rule. The gains needed for this controller are the values of $Q$ and $R$, which can be given as

$$
Q=\operatorname{diag}\left[\begin{array}{ll}
\frac{1}{(0.09)^{2}} & \frac{1}{(0.09)^{2}}
\end{array}\right], R=\frac{1}{3^{2}}
$$

Then, the gains of the LQG controller are tuned by using the intuitive method. The LQG controller also has to find the value of $Q_{f}$ and $R_{f}$. The values of these gains are

$$
Q_{f}=500, R_{f}=\operatorname{diag}[0.001 \quad 0.001]
$$

The state feedback gain matrix $F$ gain in the linear part of the CNF controller is obtained based on the damping ratio, set as 0.67 . The parameter $\alpha$ can be found by the integral of absolute error (IAE) method. Meanwhile, an optimal $\beta$ is obtained by setting the desired damping ratio of the closed loop system. Table 1 shows the numerical parameters of the CNF controller obtained during these processes.

\begin{tabular}{|c|c|c|c|c|c|}
\hline Parameter & & Value & & & Description \\
\hline \multirow[t]{2}{*}{$F$} & {$[0.2398-46.7288$} & 49.3638 & 0.0890 & 0.3439 & \multirow{2}{*}{$\begin{array}{l}\text { Obtained based on } \\
\text { damping ratio, set as } \\
\xi=0.67\end{array}$} \\
\hline & $-0.3579 \quad-0.6518$ & 23.3893 & 0.7640 & $2.3462]$ & \\
\hline$\alpha$ & 0.5826 & & & & $\begin{array}{l}\text { Nonlinear } 1^{\text {st }} \\
\text { parameter, obtained } \\
\text { by the integral of } \\
\text { absolute error (IAE) } \\
\text { method }\end{array}$ \\
\hline$\beta$ & 1000 & & & & $\begin{array}{l}\text { Nonlinear } 2^{\text {nd }} \\
\text { parameter, obtained } \\
\text { by setting desired } \\
\text { damping ratio of } \\
\text { closed loop system. }\end{array}$ \\
\hline$P$ & Diagonal $10 \times 10$ & & & & $\begin{array}{l}\text { Obtained based on } \\
\text { Lyapunov as in } \\
\text { equation }\end{array}$ \\
\hline
\end{tabular}

Table 1. Numerical parameters for CNF controller.

Two patterns and levels of cornering manoeuvres and road-holding disturbance are considered to evaluate the performance of the designed controller. Besides, a comparison is performed the results of LQR, LQG, CNF, LQR with CNF, and LQG with CNF. Three types of input disturbance patterns are used, which are fishhook, single sine input and speed bump. Figure 4 shows the three types of handling and ride test used. The characteristics of road disturbance made for the system are as shown in Figure 4(c) and the road profile is speed bump signal with a speed of $40 \mathrm{~km} / \mathrm{h}$, a 
frequency of $14.8 \mathrm{~Hz}$ and time delays of $0.18 \mathrm{~s}$. Various patterns and levels of cornering manoeuvres are considered to evaluate the roll angle and roll rate performance, as well as the robustness of the controller design. Two types of pattern input are used, single sine input with an amplitude of $2 \mathrm{rad}$ and fishhook signal with an amplitude of 1.755 rad. Figure $4(a, b)$ show both types of steering inputs. The controllers are designed and tuned to realize their performance corresponding to a torque to reduce the body roll angle and body roll rate. Therefore, from these simulations, the vehicle that is using active ARB with the LQG-CNF fusion control strategy has a good ride and handling at the same time. Moreover, computer simulations based on MATLAB software were conducted and the output responses of roll angle and roll rate are compared with the output signals from the different control strategies to verify and investigate the effectiveness of the proposed control method.

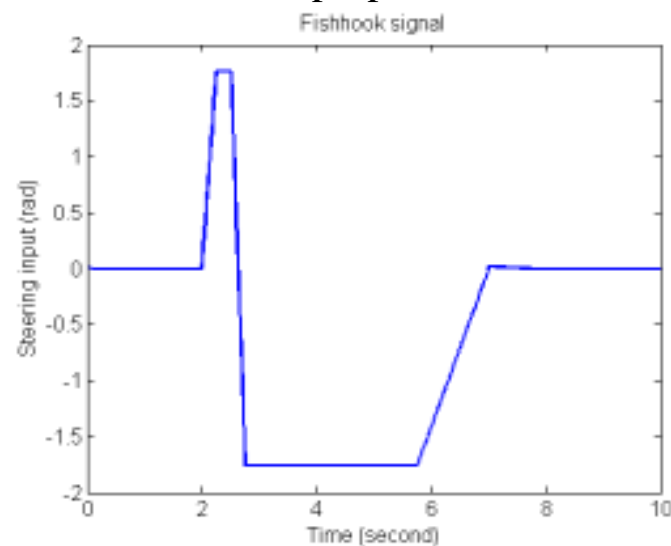

(a)

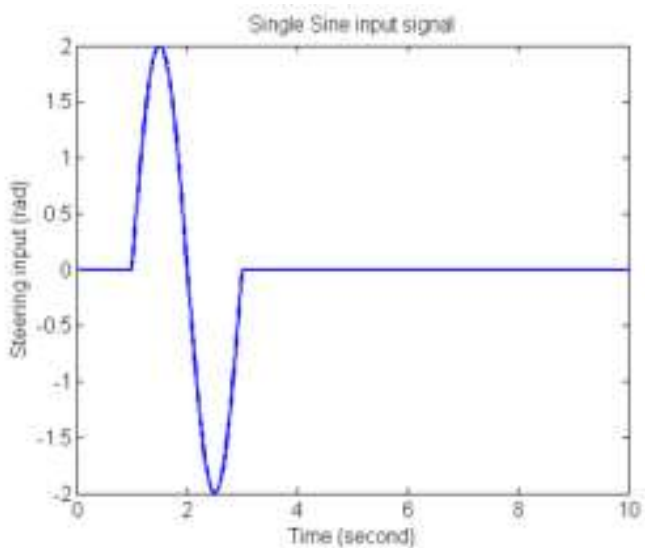

(b)

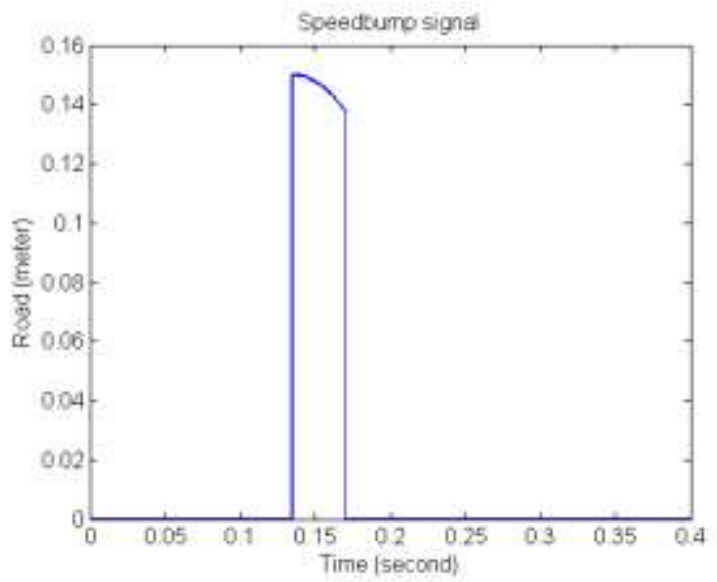

(c)

Figure 4. (a) Fishhook signal; (b) Single sine input signal; (c) Speed bump test.

Figure 5 shows the vehicle roll angle and roll rate response for the different tests which are fishhook, speed bump and single sine input. It can be seen in Figure 5(a,b), the performance of roll angle and roll rate responses are greatly reduced for the active ARB system that used CNF with the LQG controller compared with LQR. From Figure 5(c), there was $83 \%$ improvement in the maximum of body roll angle between the system with CNF with the LQG controller and the system with the CNF controller only. Meanwhile, for the body roll rate in Figure 5(d) the improvement is around $78.1 \%$. Moreover, for Figure 5(e,f) the roll angle and roll rate responses are reduced for the active ARB system that used CNF with the LQG controller compared with the LQR. 
Therefore, by using CNF with the LQG controller, the performance of the roll angle and roll rate in the handling and ride test are better and the rollover of the vehicle is decreased more than with the system connected by other controllers.

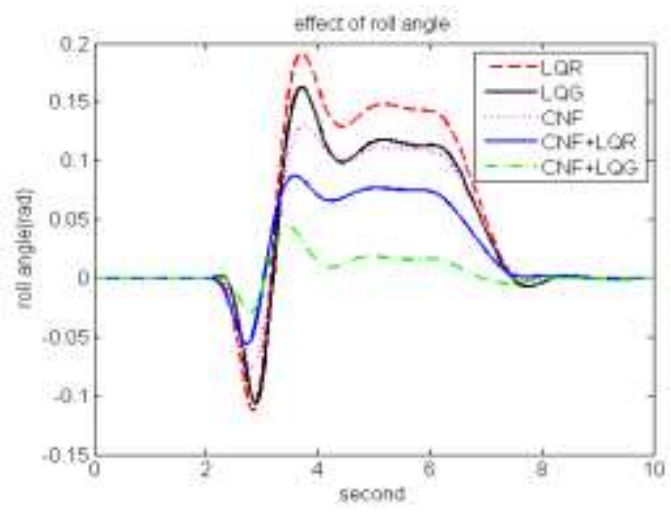

(a)

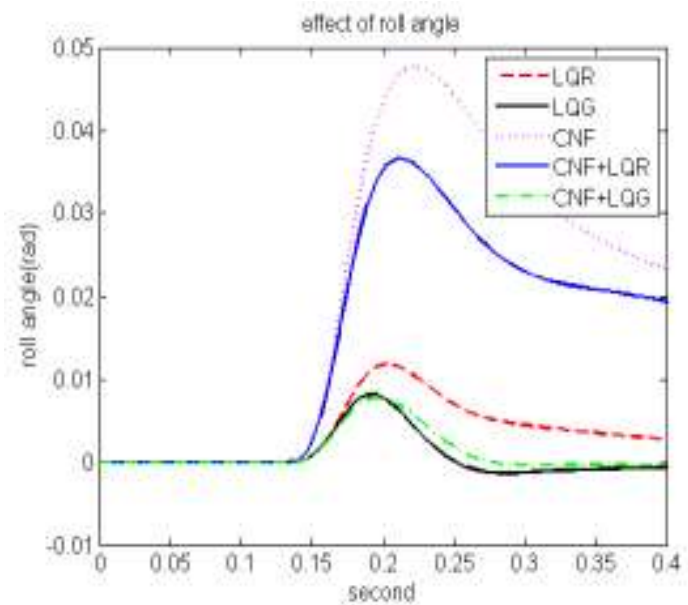

(c)

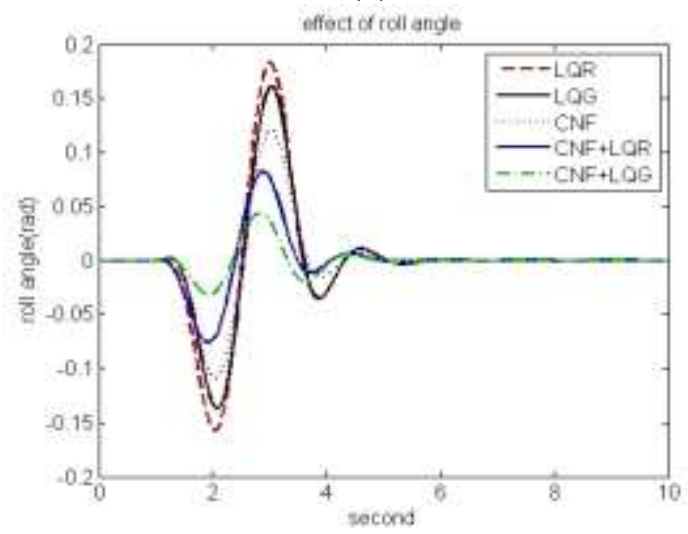

(e)

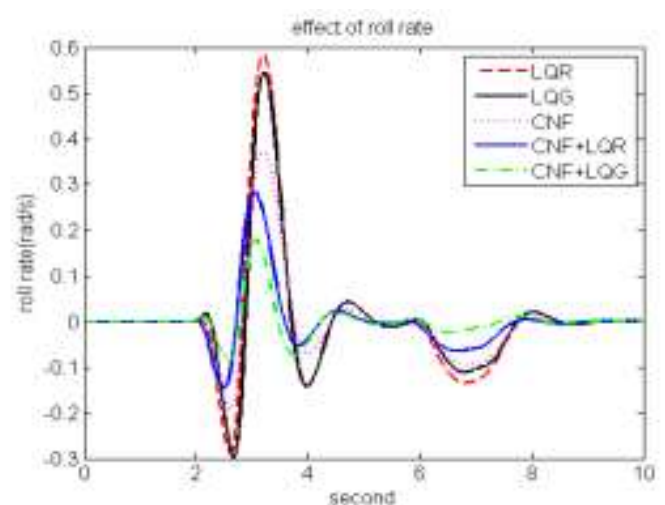

(b)

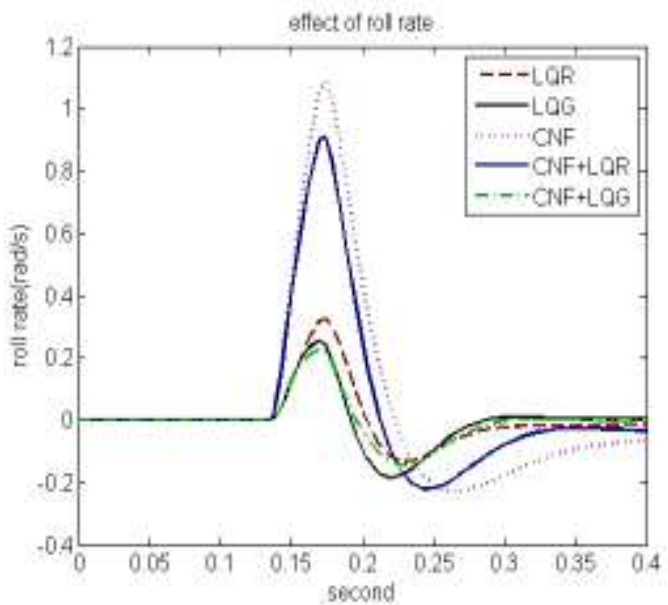

(d)

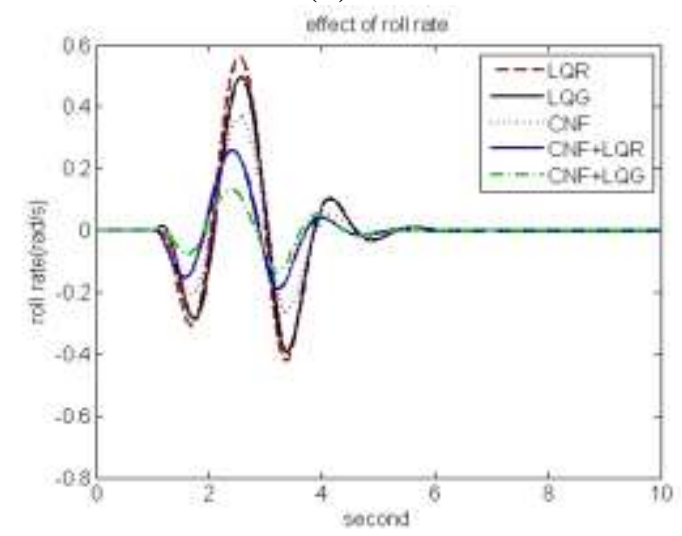

(f)

Figure 5. Fishhook test: (a) roll angle response; (b) roll rate response, Speed bump test: (c) roll angle response; (d) roll rate response, Single sine input test: (e) roll angle response; (f) roll rate response. 


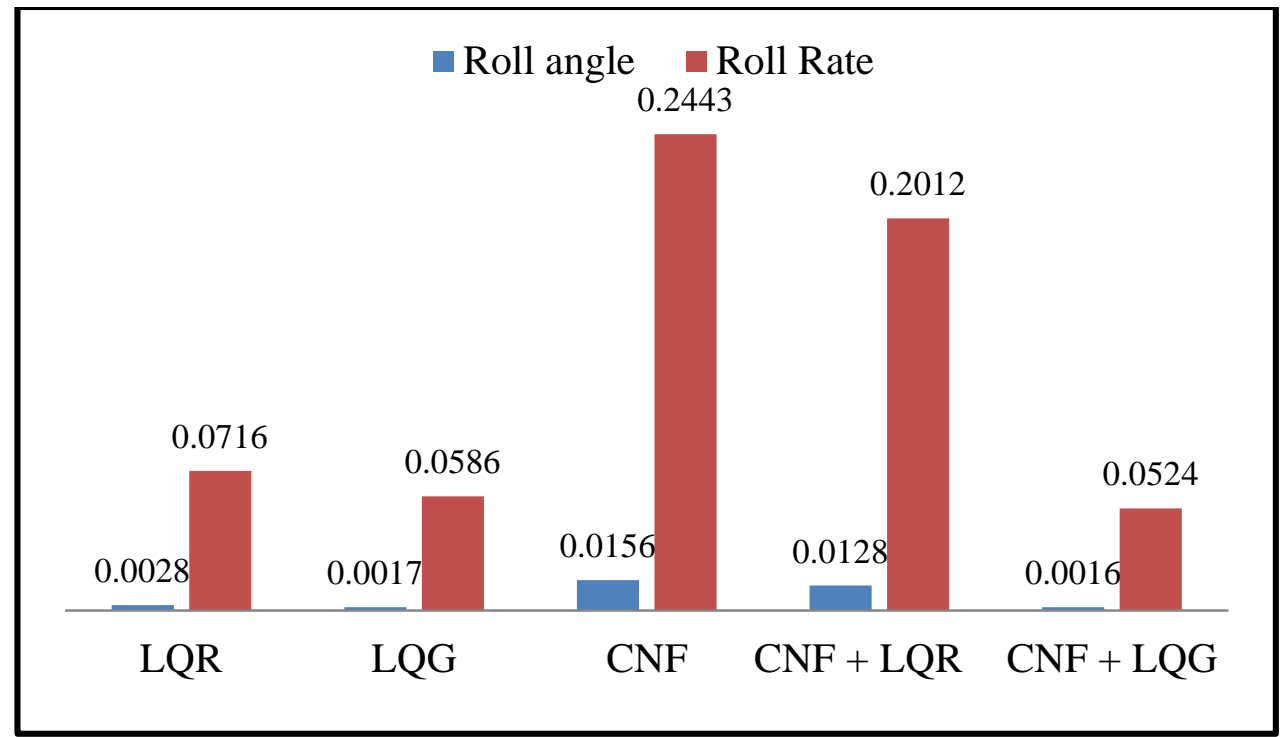

(a)

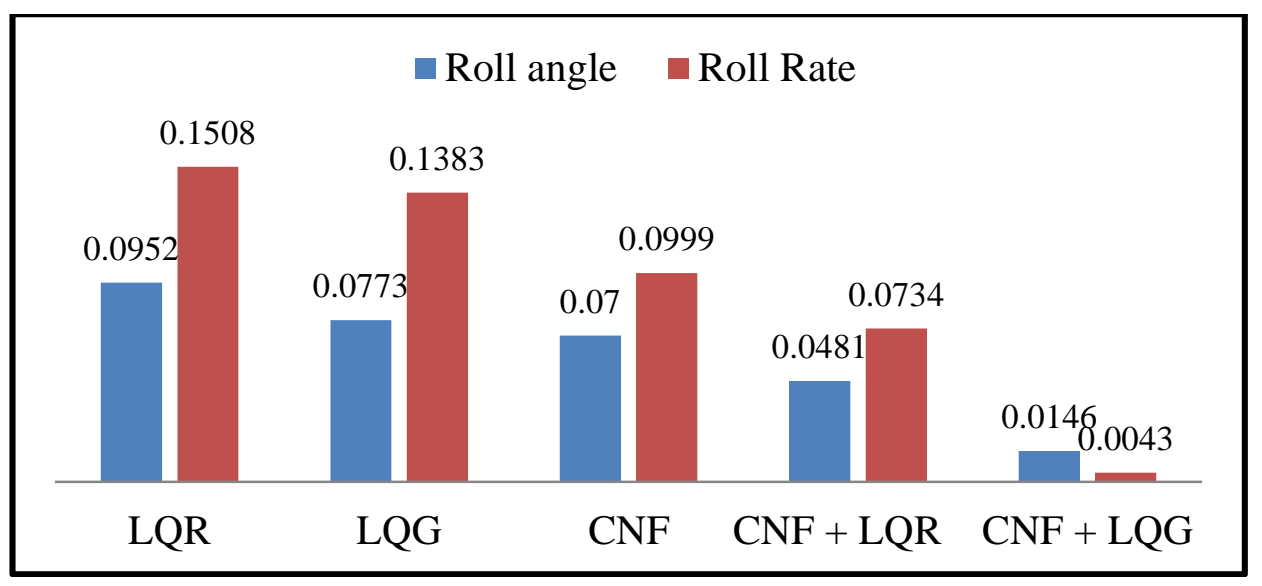

(b)

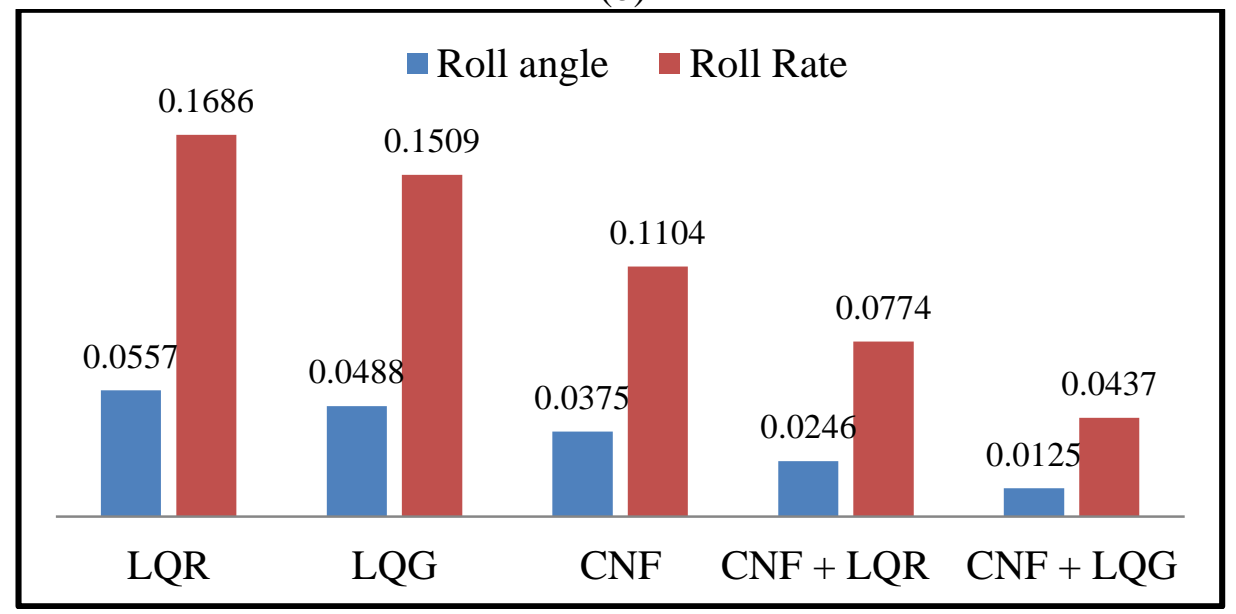

(c)

Figure 6. Comparisons between various control strategies for (a) speed bump; (b) fishhook test; (c) single sine test.

From these simulations results, the vehicles that use active ARB with CNF with the LQG controller will reduce the trade-off gap between ride comfort and improved handling at the same time. From the three tests conducted in this study, it can be shown 
the performance with an active ARB system using LQG combined with the CNF controller is better. The settling time is faster and reduces the overshoot. The improvement in the response signals is calculated by using a percentage reduction formula, which is calculated as follows [3]:

$$
\% \text { of reduction }=\frac{(\text { baseline_value }- \text { new_value })}{\text { baseline_value }} \times 100
$$

The trend indicates that further improvements in ride comfort and handling performance will bring a similar pattern but the value of the overshoot is dissimilar when using the different types of controller. Figure 5(a,b,e,f) show the signal responses for the handling, while Figure 5(c,d) show the signal performances for the ride. In the handling case, it can be shown an active ARB system using an LQR controller is of very inferior quality, while for the ride test, the system using the CNF controller only is not as good as using the combination of the LQG and CNF controller.

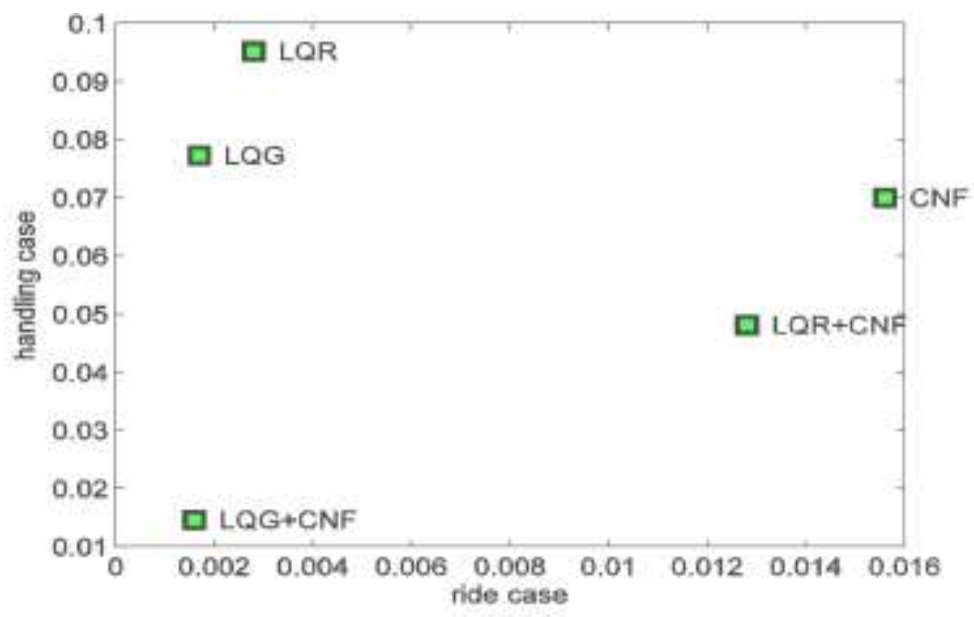

(a)

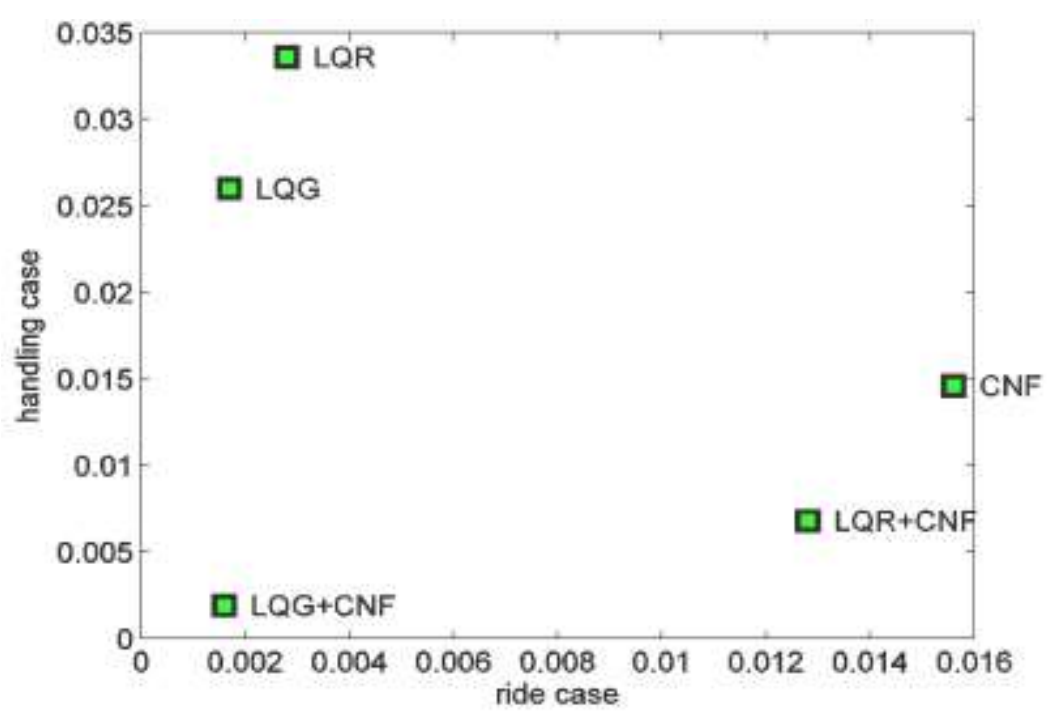

(b)

Figure 7. Handling vs ride (a) fishhook; (b) single sine input. 
Figure 6 shows the numerical results for the three different tests comparing the various control strategies using different types of controllers, which are LQR, LQG, CNF, CNF with LQR, and CNF with LQG. As the results show in these three figures, the RMS values for the roll angle and roll rate responses for the LQG-CNF control strategy have decreased more than any other control strategy. The trade-off on numerical analysis of the root mean square (RMS) value for the roll angle response is shown in Figure 7(a). This figure shows the handling test that used the fishhook manoeuvre compared with the speed bump test. It can be seen that the LQG-CNF fusion control strategy performs well for both cases in the handling and ride test. The LQR and LQG control strategy shows good handling performance but at the same time is worse on the ride case. Then, the LQR-CNF control strategy performs well with the ride, but its handling performance is worse. Besides that, the CNF control law is not so good in these two cases. Meanwhile, Figure 7(b) shows the handling test that used single sine input test compared with the speed bump test. It can be seen that the result is similar to the fishhook manoeuvre, but of a different magnitude This section has presented the simulation results of the proposed control strategy and an evaluation of the controllers' in terms of their handling and ride performance. In order to verify the effectiveness and performance of the designed controllers, various simulation tests have been carried out. The simulation results show that the LQG-CNF fusion control method is the best control strategy, with a fast response, lower settling time, reduced overshoot and improved roll angle and roll rate response.

\section{CONCLUSIONS}

This paper compares the performance of different types of control strategies, which are the system with LQR, LQG, CNF, LQR-CNF fusion and LQG-CNF fusion methods. A four-DOF vehicle model has been used to model the vehicle suspension system. AMATLAB/SIMULINK environment simulation model of the anti-roll designs for four-DOF vehicle dynamic models is used to simulate the proposed control system for an active ARB and its counterparts. According to the simulation results, the performance of the proposed system is capable of achieving better performance than its counterparts in terms of roll angle and roll rate reduction during a roll-induced manoeuvre. For future work, a more advanced control structure and control design will be investigated under various manoeuvres in order to improve the vehicle stability, which will not only benefit the handling aspect of the vehicle but also contribute to greater vehicle ride comfort.

\section{ACKNOWLEDGEMENTS}

This work is fully supported by Ministry of Higher Education Malaysia and Universiti Teknologi Malaysia under FRGS research Grant (Vote no. 4F370) and research university Grant (Vote no. 00G64). The work is also supported by Proton Sdn. Bhd.

\section{REFERENCES}

[1] Bayrakceken H, Tasgetiren S, Aslantas K. Fracture of an automobile anti-roll bar. Engineering Failure Analysis. 2006;13:732-738. 
[2] Zulkarnain N, Imaduddin F, Zamzuri H, Mazlan SA. Application of an active anti-roll bar system for enhancing vehicle ride and handling. IEEE Colloquium on Humanities, Science and Engineering. 2012. p. 260-265.

[3] ISO International Standards Organisation. Mechanical vibration and shockevaluation of human exposure to whole-body vibration, part 1: general requirements, ISO 2631-1, 2nd ed. The International Organisation for Standardisation; 15 July 1997.

[4] Yuen TJ, Rahizar R, Azman ZAM, Anuar A, Afandi D. Design optimization of full vehicle suspension based on ride and handling performance. Proceedings of the FISITA 2012 World Automotive Congress: Springer; 2013. p. 75-86.

[5] Ramasamy D, Yuan GC, Bakar RA, Zainal Z. Validation of road load characteristic of a sub-compact vehicle by engine operation. International Conference on Mechanical Engineering Research. 2013;1:3.

[6] Chumjun C, Chantalakhana C, Koetniyom S. A Compromise of comfort and handling in automotive vertical dynamics. The 20th Conference of Mechanical Engineering Network of Thailand Nakhon Ratchasima, Thailand 2006.

[7] Zamri M, Devarajan R, Mohd Razali H. Engine mount and bracket stiffness analysis. The 1st National Conference In Mechanical Engineering For Research \& Post Graduate Studies. 2010, p. 1-5.

[8] Yim S, Jeon K, Yi K. An investigation into vehicle rollover prevention by coordinated control of active anti-roll bar and electronic stability program. International Journal of Control, Automation and Systems. 2012;10:275-287.

[9] Williams DE, Haddad WM. Active suspension control to improve vehicle ride and handling. Vehicle System Dynamics. 1997;28:1-24.

[10] Zamri M, Devarajan R, Mohd Razali H. Small Sedan aerodynamics analysis. The 1st National Conference In Mechanical Engineering For Research \& Post Graduate Studies. 2010; 1-8.

[11] Cronje PH, Els PS. Improving off-road vehicle handling using an active anti-roll bar. Journal of Terramechanics. 2010;47:179-189.

[12] Danesin D, Krief P, Sorniotti A, Velardocchia M. Active roll control to increase handling and comfort. SAE Technical Paper; 2003.

[13] Yamamoto K-I, Nishimura H. Control system design of electric power steering for a full vehicle model with active stabilizer. Journal of System Design and Dynamics. 2011;5:789-804.

[14] Buma S, Ookuma Y, Taneda A, Suzuki K, Cho JS, Kobayashi M. Design and development of electric active stabilizer suspension system. Journal of System Design and Dynamics. 2010;4:61-76.

[15] Ohta Y, Kato H, Yamada D, Sato K, Fukino T, Nobuyama E, et al. Development of an electric active stabilizer system based on robust design. SAE Technical Paper; 2006.

[16] Gosselin-Brisson S, Bouazara M, Richard M. Design of an active anti-roll bar for off-road vehicles. Shock and Vibration. 2009;16:155-174.

[17] Lin R, Cebon D, Cole D. Optimal roll control of a single-unit lorry. Proceedings of the Institution of Mechanical Engineers, Part D: Journal of Automobile Engineering. 1996;210:45-55.

[18] Lin Z, Pachter M, Banda S. Toward improvement of tracking performance nonlinear feedback for linear systems. International Journal of Control. 1998;70:1-11. 
[19] Turner MC, Postlethwaite I, Walker DJ. Non-linear tracking control for multivariable constrained input linear systems. International Journal of Control. 2000;73:1160-1172.

[20] He Y, Chen BM, Wu C. Composite nonlinear control with state and measurement feedback for general multivariable systems with input saturation. Systems \& Control Letters. 2005;54:455-469.

[21] Chen BM, Lee TH, Peng K, Venkataramanan V. Composite nonlinear feedback control for linear systems with input saturation: theory and an application. IEEE Transactions on Automatic Control. 2003;48:427-439.

[22] Lan W, Thum CK, Chen BM. A hard-disk-drive servo system design using composite nonlinear-feedback control with optimal nonlinear gain tuning methods. IEEE Transactions on Industrial Electronics. 2010;57:1735-1745.

[23] Cheng G, Peng K. Robust composite nonlinear feedback control with application to a servo positioning system. IEEE Transactions on Industrial Electronics. 2007;54:1132-1140.

[24] Guoyang C, Wenguang J. Parameterized design of nonlinear feedback controllers for servo positioning systems. Journal of Systems Engineering and Electronics,. 2006;17:593-9.

[25] Peng K, Chen BM, Cheng G, Lee TH. Modeling and compensation of nonlinearities and friction in a micro hard disk drive servo system with nonlinear feedback control. IEEE Transactions on Control Systems Technology. 2005;13:708-21.

[26] Ismail MF, Sam Y, Peng K, Aripin M, Hamzah N. A control performance of linear model and the MacPherson model for active suspension system using composite nonlinear feedback. IEEE International Conference on Control System, Computing and Engineering. 2012, p. 227-233.

[27] Ismail MF, Sam Y, Sudin S, Peng K, Aripin MK. Modeling and control of a nonlinear active suspension using multi-body dynamics system software. Jurnal Teknologi. 2014;67.

[28] Pacejka HB. Tyre and vehicle dynamics. Butterworth-Heinemann, ISBN 0. 2002;7506:5.

[29] Saruchi SA, Zamzuri H, Mazlan SA, Fahami SMH, Zulkarnain N. Wheel synchronization control in steer-by-wire using composite nonlinear feedback. Applied Mechanics and Materials. 2014; 575,762-765.

[30] Zulkarnain N, Zamzuri H, Mazlan SA. Combined CNF with LQR in improving ride and handling for ground vehicle. Applied Mechanics and Materials: 2014; 575,749-752.

[31] Zulkarnain N, Zamzuri H, Sam YM, Mazlan SA, and Zainal SMHF. Improving vehicle ride and handling using lqg cnf fusion control strategy for an active antiroll bar system. Abstract and Applied Analysis. 2014; ID 698195, 1-14.

[32] Zulkarnain N, Zamzuri H, Mazlan SA. LQG control design for vehicle active anti-roll bar system. Applied Mechanics and Materials. 2014;663,146-51. 